\title{
Additional Morphological Information on Young Female Caligus Kuwaitensis (Copepoda, Siphonostomatoida) from Egyptian Marine Water Fish (Pagrus pagrus)
}

\author{
Olfat A Mahdy ${ }^{1 *}$ and Nadia M. T. Abu El Ezz²
}

${ }^{1}$ Department of Parasitology Faculty of Veterinary Medicine, Egypt

${ }^{2}$ Cairo University, El-Giza, Department of Parasitology and Animal Diseases, National Research Center, Giza, Egypt

\begin{abstract}
In the present study additional morphological features for Caligus kuwaitensis (Copepoda, Siphonostomatoida) infesting marine water fishes, (Pagrus pagrus), in Egypt was described with scanning electron microscopy. These morphological features include, sub orbicular cephalothoraxes' shield, with ridged inner wall of lunules. The arc-like structure "rugose" area, have been observed on the median surface. In the 1st pair of legs; 1st exopod bears a number of fine setules on the basal segment and has a distal spine like bristle at distal. The 2 nd exopodal segment is bearing four terminal optical stout setae each two setae are nearly equal in its length. In addition, Exopod of the 2nd leg bearing two unequal setae and with large plumose seta on posterior edge. Distinct attached spermatophores in the genital complex of young female. These additional morphological features were considered to be important and significant in accurate identifications of this Caligus species.
\end{abstract}

Keywords: Light and SEM; Young female Caligus kuwaitensis; $P$. pagrus; Egypt

\section{Introduction}

Parasitic copepods are common crustacean parasites infesting fresh, cultured and wild marine finfish [1]. Members of Caligidae are the most commonly reported species infesting fish reared in brackish and marine waters [2].

Caligus species, often referred as sea lice, are responsible for most disease outbreaks. Losses associated with Caligosis disease are the result of direct mortality, due to secondary infections and reduced growth [3]. Caligus Müller, 1785 comprises numerous species, but lack of an up to date revision of this genus makes taxonomic work difficult [4]. However, SEM studies for morphological descriptions of these copepod parasites considered to be rare $[5,6]$.

In Egypt, literatures about parasites infesting marine water fishes especially copepod were relatively rare. Unfortunately, there is a paucity of detailed morphological description of Caligus species infesting marine fish using SEM description $[7,8]$ in their study spots some light on the morphological features of some Caligus spp. (C. apodus, C. curtus, C. lunatus and C. carangis) using light microscopy. Nowadays, $P$. pagrus is one of the most common marine water fish in Egypt, there is no previous studies on morphological features of Caligus infesting them. Therefore, the present study spot more light on the fine structures of copepods: C. kuwaitensis infesting marine water fish, $P$. pagrus in Egypt using SEM.

\section{Materials and Methods}

Twenty specimen's of marine fishes (Pagrus pagrus) were collected from Al-abour market Cairo, Egypt. The samples were transferred directly in laboratory of the department of the Parasitology, Faculty of Veterinary Medicine. Cairo, University for parasitological examination and collection of parasites copepod.

\section{Collection of copepods}

The collected fish was examined microscopically for the presence of parasitic crustaceans according to [9]. The collected parasites were cleaned then preserved in $70 \%$ ethanol and dehydrated in glycerin- ethanol series, cleared in lacto phenol and mounted on glycerin-gelatin medium, according to [10].

\section{Light Microscopy (LM)}

The mounted specimens were carefully examined and morphological described. The target Caligus species was identification according to [11]. The samples were drawn by Nikon light microscopy (Japan) using camera Lucida. The terminology of the body parts and appendages were identified according to [12].

\section{Scanning Electron Microscopy (SEM)}

Clean fresh collected copepods were fixed in $2.5 \%$ glutaraldehyde, transferred to Electron Microscopy Unit, Faculty of Science, Ain Shams University, Cairo, Egypt and processed as technique described by [13]. The specimens were washed in three changes of phosphate buffered saline, dehydrated in ascending grades of ethanol and dried at critical point drier (SPI Supplies, Canada). The specimens were glued on specimen stubs and coated with $15 \mathrm{~nm}$ gold in Sputter coater (Jeol, JFC-1100 E, Japan). Finally, the specimens were examined and viewed on a Scanning Electron Microscope (Jeol, JEM-1200 EX II, and Japan).

\section{Results}

\section{Caligus kuwaitensis}

In the present study, only one Caligid species identified as C.

*Corresponding author: Mahdy OA, Parasitology Department, Faculty of Veterinary Medicine Cairo University 12211, Giza, Egypt, Tel: 20-2-35676105; E-mail: dr.olfat.mahdy@cu.edu.eg

Received October 25, 2014; Accepted January 13, 2015; Published February 13, 2015

Citation: Mahdy OA, Abu El Ezz NMT (2015) Additional Morphological Information on Young Female Caligus Kuwaitensis (Copepoda, Siphonostomatoida) from Egyptian Marine Water Fish (Pagrus Pagrus). J Aquac Res Development 6: 313 doi:10.4172/2155-9546.1000313

Copyright: ( 2015 Mahdy OA, et al. This is an open-access article distributed under the terms of the Creative Commons Attribution License, which permits unrestricted use, distribution, and reproduction in any medium, provided the original author and source are credited. 
Citation: Mahdy OA, Abu El Ezz NMT (2015) Additional Morphological Information on Young Female Caligus Kuwaitensis (Copepoda, Siphonostomatoida) from Egyptian Marine Water Fish (Pagrus pagrus). J Aquac Res Development 6: 313. doi:10.4172/2155-9546.1000313

Page 2 of 4

kuwaitensis were detected from the gills of 20 from (P.pagrus) Egyptian marine water fish [11].

Description: The described specimens based on 5 permanent slide of the parasite Figures 1A and 1B. Body 2.5 (2.25-3.12) mm long, excluding setae on caudal rami. Cephalothoracic shield suborbicular, slightly longer than wide $1.31(1.28-1.39) \times 1.20(1.22-1.35) \mathrm{mm}$ with posterior margins' of thoracic zone protruding just beyond tips of lateral zones and shallow posterior sinuses. lunules prominent, extending almost entire width of frontal plates; large sized; distance between lunules only slightly larger than their diameters.
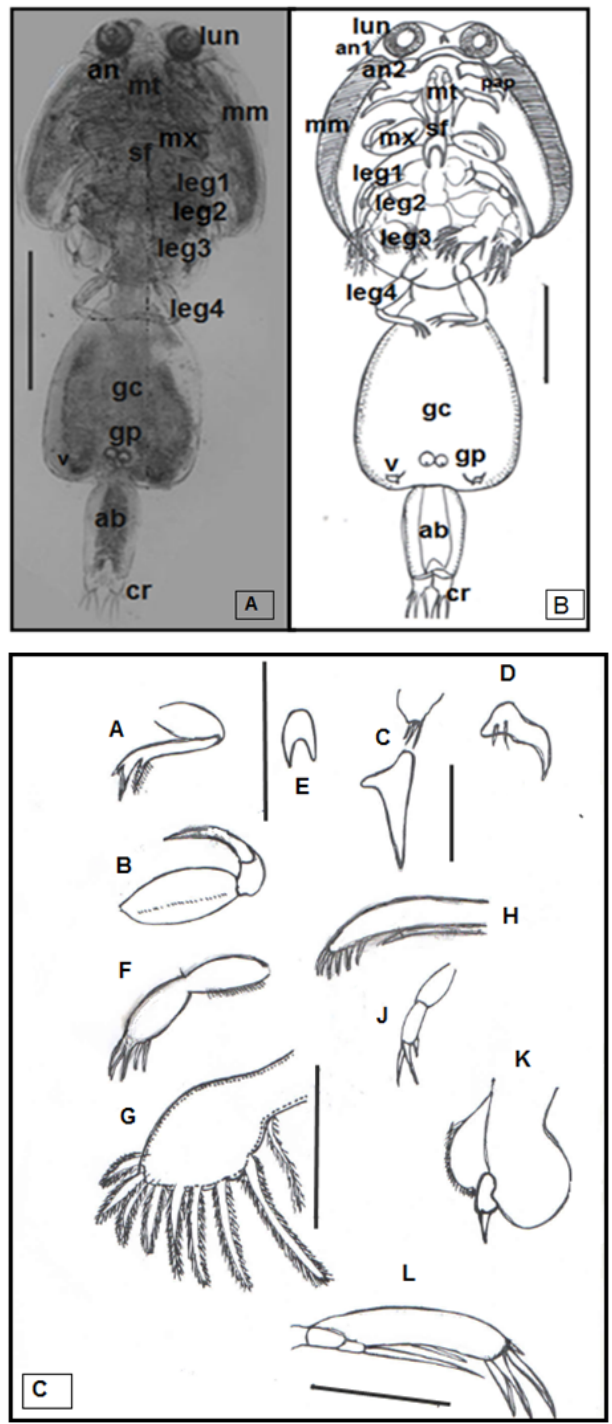

Figure 1: A and B: A light microscopic photomicrograph and drawing of young $\circ$ C. kuwaitensis: (ventral view); Well developed mouth tube (mt); Ventral view of thorax and its appendages; Abdomen and its appendages. (Abbreviations:lun, lunules, an 1, $1^{\text {st }}$ antenna; an 2, $2^{\text {nd }}$ antenna, $\mathrm{mx}$, maxillipeds; $\mathrm{mt}$, mouth tube sf, sterna furca, $\mathrm{mm}$, marginal membrane leg1-4,gc, genital complex; gpspermatophores pore, ab, abdomen, cr caudal ramus. V, vestigial appendages.scale bare $0.5 \mathrm{~mm})$. C: Young 오 Caliguskuwaitensis, (A) $1^{\text {st }}$ maxilla with serrated end (B) maxilliped (C) $2^{\text {nd }}$ maxilla (D). postantennary process with 2 sensilla near base; $(E)$ sternal furca is sharply pointed edges. $(\mathrm{F}-\mathrm{H})$ leg $1 ;(\mathrm{H})$ Endopode, $(\mathrm{F})$ exopod tip of leg 1; (J) leg 2; exopode end with spines on outer margin; $(L)$ Exopod of $4^{\text {th }}$; (K) posterior end of abdomen Scale-bars: $0.5 \mathrm{~mm}$.
Frontal plate with lunules, joined to carapace between antennules. Muscle bands connecting carapace, and frontal plate visible posterior to lunules. On the median surface, a structure (horse shoe shape) described as sucker "rugose" area. This structure is round with a central sulcus and the surface appears to be very nodular and rugose appearance Figures 2B and 2C. Fourth pedigerous segment distinctly wider than long, its demarcation from genital complex indistinct. Genital complex trapezoidal, $1.01(0.99-1.07) \mathrm{mm}$ long and $0.7(0.68$ $0.79) \mathrm{mm}$ wide, extending about all width of frontal plates (Figure $1 \mathrm{~A}$ and $3 \mathrm{~A}$ ). It has large dimensions and large round structure (vestigial appendages $=5^{\text {th }}$ leg). The marginal membrane was found to be finely striated Figure $4 \mathrm{~B}$ and medially divided into lateral halves. In the young female Figures 1A, 1B and 4D with spherical spermatophores, attached to ventro-posterior surface of genital complex. Abdomen unsegmented longer than wide and indistinctly sub conical, broadly fused to genital

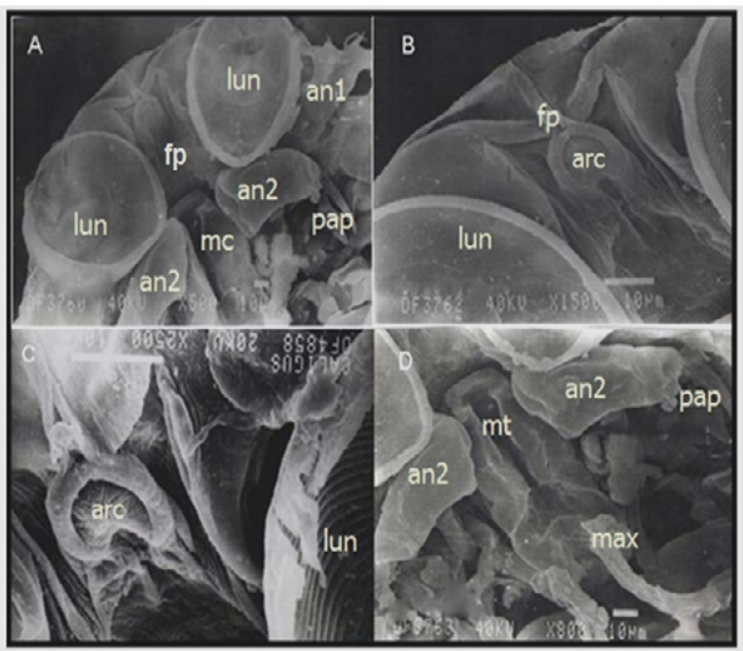

Figure 2: A-D: SEM of young $q$ C. kuwaitensis;.large sized lunules (lun), extending about all width of frontal plates (fp), $1^{\text {st }}$ antenna (an1), $2^{\text {nd }}$ antenna (an2), the mouth cone and tube ( $\mathrm{mc}$ and $\mathrm{mt}$ ), post antennal process (pap). Median arc-like structure=rugose (arc). Scale bar $=10 \mu \mathrm{m}$.

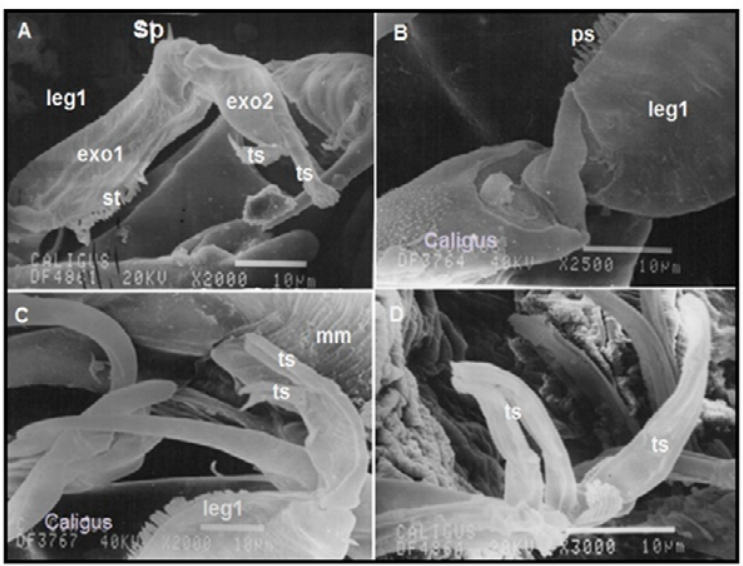

Figure 3: A-D: SEM of young $\circ$ C. kuwaitensis; $1^{\text {st }}$ exopod (exo1) of Leg1 bears a number of fine setules (st) on the basal segment. The $2^{\text {nd }}$ exopodal segment (exo2) is bearing long 4 pinnate terminal setae (ts)); each two setae are nearly equal in length on the posterior margin and has a spine like bristle (sp) at distal. Scale bar $=10 \mu \mathrm{m}$ 


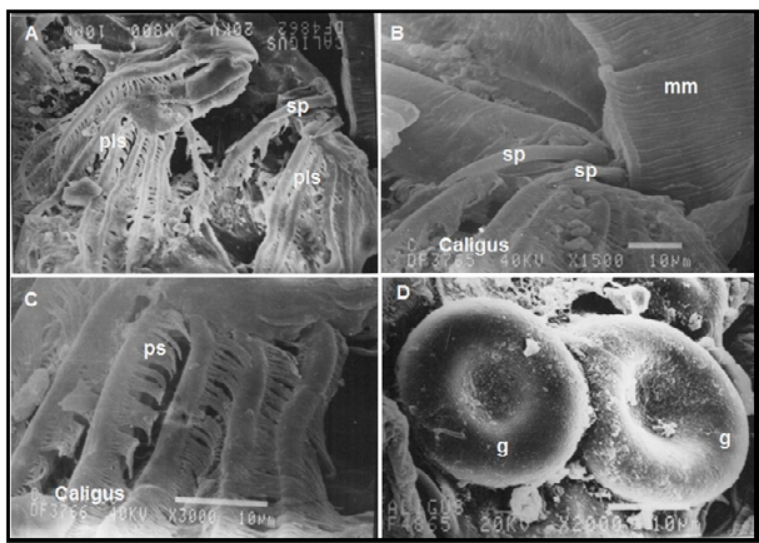

Figure 4: A-D: SEM of young $\circ$ C. kuwaitensis; (A-B) Leg 2 with large plumose seta on posterior edge (pls); unequal external spines of leg2 (sp) on exopod segments;.striated marginal membrane $(\mathrm{mm})$. (C) Leg3 with large plumose seta on posterior edge (ps); (D) Two attached spherical spermatophores $(\mathrm{g})$ of the genital complex. Scale bar $=10 \mu \mathrm{m}$.

complex, its length $0.68(0.61-0.73) \mathrm{mm}$ and $0.32(0.30-0.48) \mathrm{mm}$ wide with much longer anterior somite. Caudal ramus is flat, distinct from abdomen slightly longer than wide $(88 \times 73 \mu \mathrm{m})$, armed with one short pinnate setae in posterior-lateral corner and 3 long pinnate plumose setae on the posterior margin (Figures $1 \mathrm{~A}$ and $1 \mathrm{~B}$ ).

The mouth tube is of the typical tubular, caligoid form Figure 2D. At the level of mouth tube a continuous striated marginal membrane. The first antenna not extending beyond lateral limits of shield and without any distinguishing features. Second antenna with a typical distal segment bearing a single spine, basal segment with blunt end Figure 2A.Post antennary process, short slightly hamates' with rounded tip; 2 sensilla near base Figure 1D.

Spiniform process of first maxilla Figure 1A fairly straight, simple, without secondary armature. Second maxilla Figure 1C without distinguishing characteristics. Maxilliped Figure 1B with long, slender, unarmed corpus, about twice as long as subchelate appendage; shaft of latter twice as long as claw, distally bearing barb and small, sharp process. Sternal furca Figure 1E with subquadrate box and straight, tapering and divergent tines bearing thin flanges on lateral margins and extending posterior well beyond level of first interpodal bar.

The 1st pair of swimming legs Figures 3A-3D; 1st exopod bears a number of fine setules on the basal segment Figures $1 \mathrm{~F}-1 \mathrm{H}$ and $3 \mathrm{~A}$. The 2nd exopodal segment is bearing four optical stout long pinnate setae on the posterior margin at the terminal segment; each two setae are nearly equal in length (Figures 3C and 3D). In addition, presence of a spine like bristle at distal at the middle of 1st leg (Figure 3A). Exopod of the 2 nd leg Figure $1 \mathrm{~J}$ bearing on its distal segment one semipinnate and two setae; one long and the other is short semipinnate spine. Naked outer seta; external spines on 3 exopod segments as shown in Figure 1G and $3 \mathrm{~B}$; endopod 1st segment with row of setules on outer margin and 2nd segment with several rows of setules on outer surface.

Leg 3 (Figures 4A and 4C) protopod (apron) with row of denticles on outer edge; medial, coxal seta longer than outer, basal seta. Exopod of $4^{\text {th }}$ leg two segment; basal segment with long seta extend in distal corner the same length of the distal segment; latter bearing 3 terminal progressively long setae, apical short seta \& another distal seta (Figure 1L).
Fifth leg (Figure 1) vestigial, comprising two setae in posterolateral corner of genital segment. Sixth leg represented by single seta distomedial to fifth. Uropod subrectangular, less than half length of abdomen, with armature usual for Caligus and small tuft of setules on medial margin.

\section{Discussion}

Caligus spp. are widely distributed groups of parasites in the world seas affect wild fish of commercial significance [2]. They have potential effect on growth, fecundity and survival of wild hosts. Where, they damage their hosts directly by their attachment mechanisms and by their feeding activities.

C. kuwaitensis was described for the first time from the skin of Plotossus anguillaris in Kuwait Bay by [11]. Recently, [6] described the same species of Caligus from the gills of Doubleur Bream, Acanthopagrus bifasciatus in Dammam, Saudi Arabia. Additional location and host ( $P$. pagrus) was added to C. kuwaitensis that infest gills of marine water fishes, in Egypt. The obtained results were agreed with [12] from the aspect that Caligus spp. are known to have low hosts specificity.

The morphological features of the young $q$ collected during this study appears similarities in shape and morphmetrics to C. kuwaitensis that originally described by [11]. The body proportions of present females are also in the range given by the previous authors. The measured length of young + C. kuwaitensis in the present study was in agreement with that described by [11]. In the same time this length was smaller than that recorded by [6]. In the present study, the most characteristic features of $C$. kuwaitensis by SEM are distinct structure (arc-like) described as sucker "apparatus" or "rugose" area in between the lunules which used as sensory organ. This result agreement with [14] described the "rugose" area in genus Calgide. In addition, the lunules were appear as finely striated and the distance between them larger than their diameters this description disagreement with [15] who did not describe any striated and the distance between the lunules. Moreover, the relatively larger of this distance about 5 times than the diameter in C. acanthopagri ( $(+)$ collected from Scatophagus argus in Indonesia.

Presently, SEM study described the mouth tube is longer than wide in the C. kuwaitensis this result is agreement with $[6,16]$ who described the same feature.

In the present study, the most characteristic features by SEM of $C$. kuwaitensis are in the 1st pair of swimming legs distinct distal spine at the middle of 1st leg. This result agreement with [17] who recorded distal spine from female $C$. latigenital is obtained from the black sea bream Acanthopagrus schlegeli, cultured in Hikimoto, Japan. The 2nd exopodal segment is bearing 4 long pinnate setae on the posterior margin each two setae are nearly equal in length, this description disagreement with [16] who described 4 long pinnate setae unequal and 3 unarmed setae from C. mortis in Namibia. In addition [18], who described the middle two spines on the distal segment of the 1st legs are bifurcate in C. elongates from fish cultured off South Australia.

Moreover, SEM showed the exopod of the $2^{\text {nd }}$ leg bearing on its distal segment two setae; one long and the other short semipinnate spine. This SEM description differ from the originally description by [11] who drawing the setae were equal in the length. Concerning to, present specimen, the tip of exopod of 4 th leg which bears 4 terminal setae; the basal segment with setae in the distal corner, same length as distal segment; latter bearing 3 progressively long setae and one 
Citation: Mahdy OA, Abu El Ezz NMT (2015) Additional Morphological Information on Young Female Caligus Kuwaitensis (Copepoda, Siphonostomatoida) from Egyptian Marine Water Fish (Pagrus pagrus). J Aquac Res Development 6: 313. doi:10.4172/2155-9546.1000313

short. This description strongly agreement with [18]. Moreover, first description with two attached spherical spermatophores of the genital complex of young female this finding agree with [17] who recorded the same finding with light microscope from Japan. The present finding in Leg 5 is much reduce and represented by 2 small papillae on posterolateral margin and found the two closely fused genital opening of genital complex. The same finding by $[6,19,20]$.

\section{Conclusion}

The present study, recorded that $P$. pagrus as a new host for $C$. kuwaitensis in new locality (Egypt). The described additional SEM morphological details are important and significant for accurate identification of this Caligus species elsewhere.

\section{References}

1. Suárez-Morales E, Ho JS, Santana-Pin AM (2008) Caligus tenuifurcatus Wilson, 1937 (Copepoda, Siphonostomatoida), a parasite of centropomid and lutjanid teleosts from a coastal system of the Mexican Pacific. Acta Parasito 53: $397-403$

2. Özak AA, Demirkale I, Yanar A (2012) First Record of Two Species of Parasitic Copepods on Immigrant Pufferfishes (Tetraodontiformes: Tetraodontidae) Caught in The Eastern Mediterranean Sea. Turkish J Fisheries and Aquatic Science 12: 675-681.

3. Boxshall GA, El-Rashidy HH (2009) A review of the Caligus productus species group, with a new species, new synonymies and supplemen descriptions. Zootaxa 2271: 1-26.

4. Grobler NJ, Van As JG, Olivier PA (2002) Description of the previously unknown male of Caligus mortis Kensley, 1970 (Copepoda: Caligidae), parasite of intertidal fish from South Africa. Folia Parasitologica (Czech Republic) 49: 131 136

5. Grobler NJ, Van As JG, Olivier PA (2004) New morphological information on the parasitic copepods Caligus epinepheli Yamaguti, 1936 and Caligus rotundigenitalis Yu, 1933(Copepoda, Caligidae) from South Africa. Crustaceana 77: 187-196

6. Bayoumy EM, Baghdadi HB, Hassanain MEA (2013) Light and Scan Electron Microscopes on Caligus kuwaitensis (Copepoda: Siphonostomatoida), from
Arabian Gulf Doubleur Bream, Acanthopagrus bifasciatus, Off Dammam, Saudi Arabia Australian. J Bas Appl Sci 7: 974-978.

7. Ezz El -Dien NM, Shaheed IB (1998) On some ectoparasites causes deleterious pathological effect among Red Sea. Veterinary Medical Journal 46: 493-506.

8. Eissa IAM, El-Lamie M, Zakai M (2012) Studies on Crustacean Diseases of Seabass, Morone Labrax, in Suez Canal, Ismailia Governorate. Life Science J 9: 512-518.

9. Kabata Z (1985) Parasites and deseases of fish cultured in the tropics.

10. Pritchard MH, Kruse GO (1982) The collection and preservation of animal parasites.

11. Kabata Z, Tareen IU (1984) Description of Caligus kuwaitensis n.sp (Copepoda: Siphonostomatoida) with comments on Caligus antennatus Boxshall and Gurney, 1980. Sysmatic Parasitology 6: 57-62.

12. Ho JS, Lin CL (2004) Sea lice of Taiwan (Copepoda: Siphonostomatoida: Caligidae). The Sueichan Press, Keelung, Taiwan.

13. Topçu N (1977) Preparation of Biologic Objects for Scanning Electron Microscope.

14. Cressey R, Cressey HB (1979) The parasitic copepods of Indo- Pacific lizardfishes (Synodontidae). Advances in Parasitology 9: 1-71.

15. Yuniar AT, Palm HW, Walter T (2007) Crustacean fish parasites from Segara Anakan Lagoon, Java, Indonesia. Parasitol Res 100: 1193-1204.

16. Grobler NJ, Van As JG, Olivier PA (2002) Description of the previously unknown male of Caligus mortis Kensley, 1970 (Copepoda: Caligidae), parasite of intertidal fish from South Africa. Folia Parasitology (Praha) 49: 131-136.

17. Izawa K, Choi KH (2000) Redescription of Caligus latigenitalis Shiino, 1954 (Copepoda, Siphonostomatoida, Caligidae), parasitic on Japanese Black Sea Bream, Acanthopagrus schlegeli (Bleeker, 1854) Crustaceana 73: 995-1005.

18. Hayward CJ, Bott NJ, Itoh N, Iwashita M, Okihiro M (2007) Three species of parasites emerging on the gills of mulloway, Argyrosomus japonicus (Temminck and Schegel, 1843), cultured in Australia. Aquaculture 265: 27-40.

19. Johnson SC, Treasurer JW, Bravo S, Nagasawa K, Kabata Z (2004) A Review of the Impact of Parasitic Copepods on Marine Aquaculture. Zoology Studies 43: $229-243$.

20. Kabata Z (1979) Parasitic Copepoda of British Fishes. Ray Society, London. 